\title{
A COMPARATIVE STUDY OF THE INFLUENCE OF BODY MASS INDEX ON CLINICAL OUTCOMES OF TOTAL LAPAROSCOPIC HYSTERECTOMY IN BIRAT MEDICAL COLLEGE TEACHING HOSPITAL, MORANG, NEPAL
}

\author{
Bhanubhakta Neupane ${ }^{1 *}$, Gyanendra Man Singh Karki ${ }^{2}$, Hanoon P Pokharel ${ }^{3}$, Prerana Dahal ${ }^{4}$, Garima Bhandari ${ }^{5}$
}

\begin{abstract}
Affiliation
1. Assistant Professor / Department of Obstetrics and Gynecology, Birat Medical College and Teaching Hospital, Nepal.

2. Consultant, Department of Obstetrics and Gynecology, Birat Medical College and Teaching Hospital, Nepal.

3. Professor, Department of Obstetrics and Gynecology, Birat Medical College and Teaching Hospital, Nepal.

4. Assistant Professor, Department of Obstertrics and Gynecology, Birat Medical College and Teaching Hospital, Nepal.

5. Lecturer, Department of Obstetrics and Gynecology, Birat Medical College and Teaching Hospital, Nepal.
\end{abstract}

\section{ARTICLE INFO}

Received : 04 February, 2021

Accepted : 26 March, 2021

Published : 15 June, 2021

(C) Authors retain copyright and grant the journal right of first publication with the work simultaneously licensed under Creative Commons Attribution License CC - BY 4.0 that allows others to share the work with an acknowledgment of the work's authorship and initial publication in this journal.

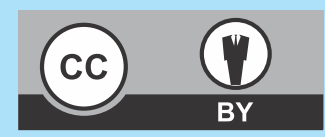

\section{ORA 239}

DOI: https://doi.org/10.3126/bjhs.v6i1.37642

\section{* Corresponding Author}

Dr. Bhanubhakta Neupane Assistant Professor

Department of Obstetrics and Gynecology Birat Medical College and Teaching Hospital, Nepal Email: bhanubutwal@gmail.com ORCID: https://orcid.org/0000-0002-0308-5236

\section{Citation}

Bhanubhakta Neupane, Gyanendra Man Singh Karki, Hanoon P Pokharel, Prerana Dahal, Garima Bhandari. A comparative study of the influence of body mass index on clinical outcomes of total laparoscopic hysterectomy in Birat Medical College teaching hospital, Morang, Nepal BJHS 2021;6(1)14. $1383-1387$.

\section{ABSTRACT}

\section{Introduction}

Although laparoscopy is a safe route of hysterectomy as it provides better view of abdominal anatomy, facilitates meticulous hemostasis and reduces surgical morbidity, laparoscopic hysterectomy in overweight and obese women may pose an increased risk of intraoperative and postoperative complications as omental fat and limited manipulation of instruments may render operation difficult.

\section{Objectives}

The aim of the study is to evaluate the impact of Body Mass Index (BMI) on the clinical outcome of total laparoscopic hysterectomy.

\section{Methodology}

This is a comparative cross-sectional study conducted in 190 patients who underwent total laparoscopic hysterectomy (TLH) in Department of Obstetrics and Gynecology of Birat Medical College, Teaching Hospital from July, 2019 to November 2020.Ninety five patients were enrolled in high BMI group and normal BMI group each

\section{Result}

Mean $\mathrm{BMI}$ was $28.90 \pm 2.27\left(\mathrm{Kg} / \mathrm{M}^{2}\right)$ in high $\mathrm{BMI}$ group and $23.54 \pm 1.14\left(\mathrm{Kg} / \mathrm{M}^{2}\right)$ in normal BMl group. Urinary tract injury occurred in 4 (4.21\%) cases in high BMI group and 2 (2.1\%) cases in normal BMI group. Intraoperative and immediate postoperative complication were similar in both groups.

\section{Conclusion}

Intraoperative and postoperative complications were similar in both the groups. Patients with high BMI have no increased risk of complications during total laparoscopic hysterectomy.

\section{KEYWORDS}

Body mass index, hysterectomy, laparoscopic, obesity. 


\section{INTRODUCTION}

Excess of body weight has become a global pandemic and the prevalence of overweight and obesity is increasing at an alarming rate. ${ }^{1,2}$ The prevalence of obesity among women worldwide increased from $6.4 \%$ in 1975 to $14.9 \%$ in 2014 . If present trends continue, global obesity prevalence among women will surpass $21 \%$ by $2025 .{ }^{3}$ Body mass index (BMI) is calculated by dividing the weight in kilograms by square of height in meters. The World Health Organization defines a body mass index (BMI) under $18.5 \mathrm{~kg} / \mathrm{m}^{2}$ as underweight, a BMI between 18.5 and $24.9 \mathrm{~kg} / \mathrm{m}^{2}$ as normal, a BMI between 25 and $29.9 \mathrm{~kg} / \mathrm{m}^{2}$ as overweightand a $\mathrm{BMI}$ of $30 \mathrm{~kg} / \mathrm{m}^{2}$ or more as obese.

Advantages of laparoscopic hysterectomy include less blood loss, less post-operative pain, shorter hospital stay, faster recovery and better cosmetic outcome. ${ }^{5}$ Obesity has long been considered as a relative contraindication to perform laparoscopic surgery. ${ }^{6}$ Laparoscopic surgery in the obese gynecologic patient can be technically challenging. Establishment and maintenance of the pneumoperitoneum pose significant difficulty, given the thickness of the abdominal wall and the amount of preperitoneal fat. Movement and placement of laparoscopic instrument and visualization of operating field may be difficult during the TLH due to increased skin thickness and excess omental fat. ${ }^{7}$ Obesity is associated with several comorbidities such as coronary heart disease and diabetes mellitus ${ }^{8}$ and the comorbidites negatively affect surgical outcome. ${ }^{9}$ Butwith improved instrumentation and techniques, many advanced laparoscopic operations have been seen to be safe and feasible in women with high BMI. ${ }^{10,11}$

But there is still a debate about the influence of overweight and obesity on intraoperative and postoperative complications of laparoscopic hysterectomy. In this study, we aim at assessing impact of high BMI on the perioperative outcome of total laparoscopic hysterectomy in Birat Medical College Teaching Hospital.

\section{METHODOLOGY}

This is a comparative cross sectional study conducted in 190 patients who underwent total laparoscopic hysterectomy (TLH) in Department of Obstetrics and Gynecology of Birat Medical College, Teaching Hospital from July, 2019 to November 2020. The study was approved by Institutional Review Committee of Birat Medical College (Ref: IRC-PA030/2076-77). One hundred and ninety patients undergoing total laparoscopic hysterectomy for various benign gynecological conditions during above mentioned period were enrolled in the study. The patients were categorized in two groups: group 1 included the patients with high Body Mass Index (BMI 25 or more ) and group 2 included patients with normal BMI ( BMI between 18.5 to 24.9).The sample size was calculated considering $80 \%$ of power of study with $5 \%$ of level of acceptance. Minimum number of subjects required for the study in each group was calculated to be 95 . An informed written consent was taken from each patient before undergoing operation. Self structured Performa was used to collect all necessary information.
Women with malignancy of genital organs were excluded from the study. Over the study period, 95 patients with high BMI (overweight and obese) underwent total laparoscopic hysterectomy. For the comparison purpose, same numbers of patients with normal BMI were enrolled in the study by continuous sampling.

The primary objective was to study the effect of high BMI on the surgical outcome of women undergoing total laparoscopic hysterectomy. The outcome of total laparoscopic hysterectomy was studied in terms of time taken for the surgery, conversion to laparotomy, intraoperative complications like excessive bleeding during surgery, urinary tract injury (urinary bladder and ureter), bowel injury, need for blood transfusion and total days of postoperative hospital stay. These parameters were compared between the two groups. In order to prove minimal interoperator variability, the operations were performed by two surgeons with minimum of five years of experience in minimal invasive gynecological surgery.The observation parameters were saved in Microsoft excel and statistical analysis was done with IBM SPSS version 23 . The continuous data were presented as mean and standard deviation while categorical data were presented as frequency and percentage. T test and Chi Square test were applied for continuous and categorical data respectively. A p-value less than 0.05 was considered statistically significant. The duration of the operation was defined as time taken from making the abdominal ports to closure of abdominal ports.

Four ports were made in anterior abdominal wall. A primary trocar of $10 \mathrm{~mm}$ diameter with blunt obturator was directly inserted through the umbilicus or supraumbilical region, according to the size of the uterus. Three $5 \mathrm{~mm}$ trocars placed through accessory ports. Bipolar electrosurgical unit was used for cautery of tissue. Both round ligaments were cauterized and cut. Infundibulopelvic ligament were cauterized and cut in cases requiring oophorectomy and utero-ovarian ligaments were cauterized and cut when one or both varies needed to be preserved. Uterovesical fold was dissected and urinary bladder was pushed downward. Then, both uterine arteries were skeletonized and cauterized and cut. Finally, cardinal ligaments on both side cauterized and cut. Colpotomy was performed around cervicovaginal junction using a monopolar cautery, and the specimen was removed by means of the vaginal route. Large uterus and fibroids which could not be removed via vaginal route were removed by morcellation. The vaginal cuff was closed with intracorporeal suturing using delayed absorbable suture.

Patients were discharged as soon as they were clinically well and felt comfortable to go home. Blood transfusion was done if post operative hemoglobin level was less than 8 grams/ dl.

\section{RESULTS}

One hundred and ninety women who underwent total laparoscopic hysterectomy (TLH), 95 in high BMI group and 95 in normal BMI group, were enrolled in the study. Maximum number of patients were in $40-60$ years age group. (Table 1)

$\begin{array}{rrr}\text { Birat Journal of Health Sciences } & \text { 1.384. }\end{array}$




Table 1: Age distribution.
\begin{tabular}{|l|c|c|}
\hline \multicolumn{1}{|c|}{ Age ( years) } & High BMI & Normal BMI \\
\hline $30-40$ & 17 & 18 \\
\hline $40-50$ & 36 & 32 \\
\hline $50-60$ & 25 & 26 \\
\hline More than 60 & 17 & 19 \\
\hline Total & 95 & 95 \\
\hline
\end{tabular}

Mean age, parity and height were comparable in both groups. (Table 2 ) Mean BMI was $28.90 \pm 2.27$, ranging from 25.23 - 34.99 in high BMI group and $23.54 \pm 1.14$, ranging from 20.06-24.91 in normal BMI group.

\begin{tabular}{|c|c|c|c|c|c|}
\hline \multirow[t]{2}{*}{ Particulars } & \multicolumn{2}{|c|}{ High BMI (n=95) } & \multicolumn{2}{|c|}{ Normal BMI (95) } & \multirow[t]{2}{*}{$P$ value } \\
\hline & Mean \pm SD & Range & Mean \pm SD & Range & \\
\hline Age (in years) & $49.85 \pm 10.17$ & $32-64$ & $49.37 \pm 10.39$ & $32-81$ & 0.74 \\
\hline $\begin{array}{l}\text { Parity Mean } \\
\text { median }\end{array}$ & $\begin{array}{l}2.64 \pm 0.71 \\
3\end{array}$ & $1-4$ & $\begin{array}{l}2.67 \pm 1.13 \\
3\end{array}$ & $1-7$ & 0.85 \\
\hline Height (centimeters) & $156.52 \pm 4.57$ & $145-172$ & $156.90 \pm 4.94$ & $147-170$ & $0 \quad 0.99$ \\
\hline Weight (in Kg) & $70.79 \pm 5.52$ & $49-83$ & $59.77 \pm 7.2$ & $45-85$ & 0.41 \\
\hline $\begin{array}{l}\text { Operating time } \\
\text { (minutes) } \\
\text { Mean } \pm S D\end{array}$ & $73.19 \pm 11.67$ & $52-105$ & $58.00 \pm 10.98$ & $40-100$ & 0.09 \\
\hline $\begin{array}{l}\text { Total hospital stays } \\
\text { (in days) } \\
\text { Mean } \pm \text { SD }\end{array}$ & $3.46 \pm 0.68$ & $3-6$ & $3.05 \pm 0.47$ & 3-4 & 0.74 \\
\hline
\end{tabular}

The common indications for hysterectomy were abnormal uterine bleeding, ovarian cyst and fibroid uterus. Table 3

Table 3: Indications of TLH
\begin{tabular}{|l|cc|rl|}
\hline Indications for TLH & \multicolumn{2}{|c|}{$\begin{array}{c}\text { High BMI } \\
(\mathbf{n}=95)\end{array}$} & \multicolumn{2}{|c|}{ Normal BMI (n=95) } \\
\hline Abnormal Uterine Bleeding & 24 & $(25.26 \%)$ & 27 & $(28.42 \%)$ \\
\hline Fibroid & 22 & $(23.15 \%)$ & 14 & $(14.73 \%)$ \\
\hline Chronic Pelvic Pain & 15 & $(15.78 \%)$ & 17 & $(17.89 \%)$ \\
\hline Ovarian cysts & \multicolumn{2}{|c|}{$19(20 \%)$} & 21 & $(22.10 \%)$ \\
\hline Endometriosis & 5 & $(5.26 \%)$ & 7 & $(7.36 \%)$ \\
\hline Cervical precancer & 5 & $(5.26 \%)$ & 3 & $(3.15 \%)$ \\
\hline Postmenopausal bleeding & 3 & $(3.15 \%)$ & 5 & $(5.26 \%)$ \\
\hline Endometrial hyperplasia & 2 & $(2.10 \%)$ & 0 & $(0.0 \%)$ \\
\hline Pyometra & 0 & $(0.0 \%)$ & 1 & $(1.05 \%)$ \\
\hline Total & 95 & $(100 \%)$ & 25 & $(100 \%)$ \\
\hline
\end{tabular}

Urinary tract injury rate was $4.21 \%$ (4/95) in high BMI group and $2.1 \%(2 / 95)$ in normal BMI group. (Table 4)

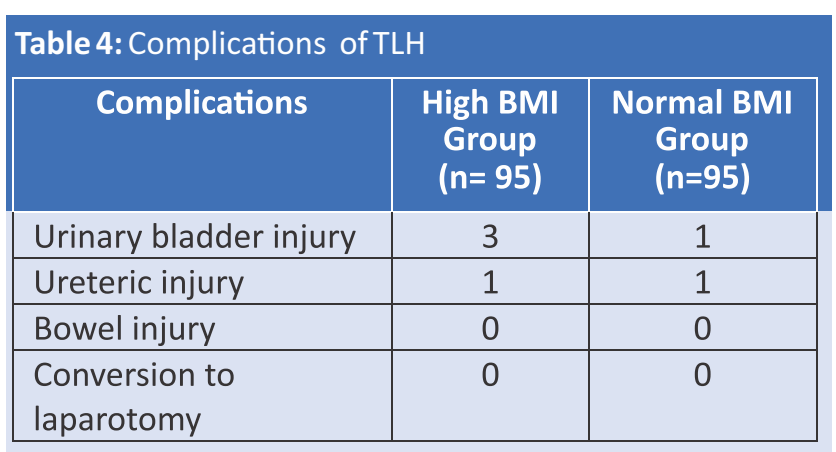

Ten women in high BMI group and nine women in normal $\mathrm{BMI}$ group received blood transfusion in immediate postoperative period. Five women in high BMI group and 3 women in normal BMI group had excessive intraoperative bleeding and blood was transfused postoperatively. Other 11 women who needed blood transfusion postoperatively had lower hemoglobin level preoperatively.

There were no conversion to laparotomy, no major vessel injury and no bowel injury. Mean operating time was $73.19 \pm 11.67$ minutes (range: 52-105 minutes) in high BMI group and 58.00 \pm 10.98 minutes (range: 40-100 Minutes) $(P=0.09)$.

Mean postoperative hospital stay was $3.46 \pm 0.68$ days (range: 3-6 days) in high BMI group and 3.05 \pm 0.47 days (range: 3-4days), the difference was statistically not significant ( $p=0-.74)$.

\section{DISCUSSION}

A high Body Mass Index (BMI) is reported to be an independent risk factor for difficulty in performing total laparoscopic hysterectomy (TLH). ${ }^{12}$ Laparoscopic hysterectomy in obese patients is certainly associated with burdens and risks. These problems may be overcome by skilled surgeons, anesthetists, and medical staff in the operating room. ${ }^{3}$ Laparoscopic hysterectomies are feasible, safe, and provide shorter hospital stays and less blood loss in the obese patient population. ${ }^{5,13,14}$ Appropriate patient selection and an experienced surgical team can help eliminate differences in complication rates in high BMI patients. Patients with a high BMI may achieve the greatest benefit from laparoscopic surgery. ${ }^{13}$

In our study, Mean operating time was $73.19 \pm 11.67$ minutes (range:52-105 minutes) in high BMI group and 58.00 \pm 10.98 minutes (range: 40-100 Minutes) in normal BMI group.. The difference was statistically not significant $(P=0.09)$. In a study by O'Hanlan KA et al, mean duration of surgery was 153.7 minutes in ideal BMI group $(n=150), 152.2$ minutes in overweight group ( $\mathrm{n}=95$ ) and 164.9 minutes in obese group $(n=78)$. The difference was statistically not significant (p0.185). ${ }^{7}$ Guraslan $\mathrm{H}$ et al(2015) reported the mean operation time significantly higher in obese (128 $\pm 32 \mathrm{~min}$ ) and morbidly obese patients (130 $\pm 21 \mathrm{~min})$ than in non-obese $(110 \pm 23$ $\mathrm{min}$ ) patients. The most important reason for this difference is the restricted movement of the laparoscopic instruments due to the thick subcutaneous fat tissue. ${ }^{13}$ Median operating time was 87.5 minutes (range 25-360 minutes) for TLH in 100 women with $>30$ BMI $^{15}$ Compared with the normal-weight group, the obese group had significantly longer operation times (172 \pm 48.1 min. vs. $207 \pm 62.3$ min., $\mathrm{P}=0.04){ }^{3}$

Similarly, in the study by Bardens $D$ et al, mean operative time was $129.0 \pm 58.6$ minutes in normal weight group $(n=90), 135.4 \pm 46.9$ minutes in overweight group $(n=47)$ and $154 \pm 64.2$ minutes in obese women with $\mathrm{BMI}>30(n=52)$. The difference was statistically significant. It is very likely that this was a result of the longer time needed to visualize the structures in the deep pelvis as the amount of peritoneal 
fat is increased. But the operating time seems not to have a relevant impact on the surgical outcomes. ${ }^{14}$ In another study, the duration of TLH was $52.26 \pm 20.75$ minutes in nonobese $(n=148)$ and $56.86 \pm 18.22$ minutes in obese $(n=105)$ women. The difference was statistically not significant. ${ }^{9}$

Length of hospital stay was similar in all BMI groups. ${ }^{14}$ O'Hanlan KA et al (2003) found that mean length of hospital stay after TLH was 1.8 days in ideal weight group, 1.8 days in overweight group and 2.2 days in obese group. ${ }^{7}$ In a systematic review by Blikkendaal MD et al (2015), mean duration of hospital stay in obese women after TLH was $3.6 \pm 1.6$ days. $^{16}$

Mean length of hospital stay after TLH was 2.9 days \pm 1.3 days in both obese and non obese women. ${ }^{13}$ Similarly, average days of postoperative hospital stay in obese patients after TLH was one day, ranging from 1-5 days. ${ }^{15}$ In another study by Otake A et al (2019), mean postoperative hospital stay was 5 (3-13) days in normal BMI group, 5 (4-10) days in overweight group and 5 (4-37) days in obese group. In our study, mean postoperative hospital stay was $3.46 \pm 0.68$ days (range: 3-6 days) in high BMI group and 3.05 \pm 0.47 days (range:3-4days), the difference was statistically not significant ( $p=0-74)$.

O' Hanlan KA et al (2003) analyzed 323 cases of TLH, of which 150 had ideal BMI, 95 were overweight (BMI 25-30) and 78 were obese $(\mathrm{BMI}>30)$. Urological complications occurred by $3.5 \%$ in ideal $\mathrm{BMI}$ group and by $2.89 \%$ in high $\mathrm{BMI}$ group. One colon injury occurred in ideal BMI group but no colon injury in high BMI women. In another study, bowel injury occurred in one patients $(1 / 44)$ in <30 BMI women and $1(1 / 75)$ in $>30 \mathrm{BMl}$ group. Urinary bladder injury occurred in 2 (2/44) patients in < $30 \mathrm{BMI}$ group and in 1 $(1 / 75)$ patient in $>30 \mathrm{BMI}$ group. Complication rates were similar in both groups. ${ }^{13}$ There were no urological injury, colonic injury and major vessel injury during TLH in women with higher BMI. ${ }^{5,14,15}$

Otake A et al (2019) analyzed 165 TLH cases where 117 women had normal BMI and 48 had > 25 BMI. No urinary bladder injury occurred in either group, 2 bowel injury occurred in high BMI women and one ureteric injury in normal BMI group. Complication rates were similar in normal and high group. ${ }^{3}$ Similarly, Chopin N et al (2009) analyzed 1460 women who underwent TLH among which 1021(69.9\%) had normal BMI, 338 (23.2\%) were overweight patients and 101 $(6.9 \%)$ were obese $(\mathrm{BMI}>30)$. Urinary bladder injury occurred in $9(0.9 \%)$ in normal BMI group, in $3(0.9 \%)$ in overweight group and $2(2.0 \%)$ in obese group. Ureteric injury occurred in $3(0.3 \%)$ in normal weight women but no ureteric injury occurred in overweight and obese group. One patient had gastrointestinal tract injury only in normal weight group. They concluded that obesity does not increase the risk of intra- and postoperative complications. ${ }^{17}$ Our study also revealed similar findings. In this study, urinary tract injury rate was $3.15 \%$ (6/190). There were 4 urinary tract injury in high BMI group (4.21\%) and 2 in normal BMI group (2.10\%). Urinary bladder injury occurred in 3 patients in high BMI group and 1 in normal BMI group. Thermal ureteric injury occurred in one patient in each group. Urinary bladder injuries in both groups were due to dense adhesion of urinary bladder with anterior uterine wall either due to previous Caesarean section or endometriosis, which were not directly attributable to Body Mass Index (BMI). All urinary bladder injuries occurred during dissection of urinary bladder from anterior uterine surface. All the bladder injuries were identified during surgery and repaired immediately by laparoscopy. Ureteric injures were all themal injuries by bilpolardiathermy and managed with Double J stenting after cystoscopy and ureterorenoscopy with the help of urologist. There were no bowel injury or major vessel injury in our study in both normal and high BMI group. We concluded that TLH can be carried out among obese patients in a feasible and safe way.

Morgan-Ortiz F et al (2013) analyzed 209 women with TLH, among which 77 had normal weight, 82 were overweight and 50 were obese. The overall frequency of conversion to laparotomy was $1.43 \%(n=3)$, one in each group. Two conversions were due to bowel injury ( 1 in overweight group and 1 in obesity group), and 1 conversion in normal BMI group was due to technical difficulties. ${ }^{6}$ The conversion rate of obese and morbidly obese patients was similar to those of non-obese patients. ${ }^{13}$ No patients were converted to laparotomy because of difficulties attributed to high BMI.,

In $100 \mathrm{TLH}$ patients with $\mathrm{BMI}>30$, there were 2 (2\%) cases where laparotomy was needed to complete hysterectomy. ${ }^{15}$ Bogani $\mathrm{G}$ et al Conversion to laparotomy was necessary in $2 / 24$ (8.3\%) obese patients. ${ }^{5}$ Conversion to laparotomy were required in $3.4 \%$ in normal $\mathrm{BMI}$ group, $5.6 \%$ in overweight women and $4 \%$ in obese women. The rate was similar in all groups. ${ }^{17}$

In another study, among $148 \mathrm{TLH}$ in nonobese women and $105 \mathrm{TLH}$ in obese women, three cases $(2.0 \%)$ in none obese group and one case $(0.95 \%)$ in obese group needed conversion to laparotomy. But the conversion to laparotomy was not attributed to BMI or reasons associated with it. ' In our study, there were no conversion to laparotomy in both groups. Difficulties during operation were experienced due to type of disease like endometriosis, large fibroids and adhesions due to previous intraabdominal adhesions. Higher BMI does not seem to pose any difficulty in operation.

\section{CONCLUSION}

Surgical outcomes are similar after total laparoscopic hysterectomy in patients with normal Body Mass Index 
(BMI) and high BMI. Total laparoscopic hysterectomy can be carried out safely in patients with high BMI.

\section{LIMITATIONS OF THE STUDY}

This is a single centre study. Multicentre study including large scale of participants would be better to substantiate the findings of this study.

\section{ACKNOWLEDGEMENT}

I would like to acknowledge Institutional Review Committee of Birat Medical College for approving my proposal for the study. I would like to thank all the faculty members of Department of Obstetrics and Gynecology of Birat Medical College. I $\mathrm{m}$ also thankful to all the participants who took part in the study.

\section{CONFLICT OF INTEREST}

None

\section{FINANCIAL DISCLOSURE}

We declare that any financial benefit from any person or organization is not taken to conduct this study.

\section{REFERENCES}

1. Redinger RN. The prevalence and etiology of nongenetic obesity and associated disorders. South Med J 2008;101:395-399.

2. Wang Y, Beydoun MA (2007) The obesity epidemic in the United States-gender, age, socioeconomic, racial/ethnic, and geographic characteristics: a systematic review and metaregression analysis. Epidemiol Rev 29:6-28. doi:10.1093/epirev/ mxm007.

3. Otake A, Horai M, Tanaka E, Toda A, Miyoshi Y, Funada R, et al. Influences of total laparoscopic hysterectomy according to body mass index (underweight, normal weight, overweight, or obese). Gynecol Minim Invasive Ther2019;8:19-24.

4. World Health Organization. Global Database on Body Mass Index, BMI Classification. Available from: http://www.apps.who. int/bmi/ index.

5. Borahay MA, Tapısız ÖL, Alanbay I, Kılıç GS. Outcomes of robotic, laparoscopic, and open hysterectomy for benign conditions in obese patients. J Turk Ger Gynecol Assoc. 2018 Jun 4;19(2):72-77. doi: 10.4274/jtgga.2018.0018. Epub 2018 Apr 27. PMID: 29699956; PMCID: PMC5994808.

6. Morgan-Ortiz F, Soto-Pineda JM, López-Zepeda MA, PerazaGarayFde J.Effect of body mass index on clinical outcomes of patients undergoing total laparoscopic hysterectomy.Int J Gynaecol Obstet. 2013 Jan;120(1):61-4. doi: 10.1016/j.ijgo.2012.08.012. Epub 2012 Nov 24.

7. O'Hanlan KA, Lopez L, Dibble SL, Garnier AC, Huang GS, Leuchtenberger M. Total laparoscopic hysterectomy: body mass index and outcomes.Obstet Gynecol. 2003 Dec;102(6):1384-92

8. DeMaria EJ, Carmody BJ (2005) .Perioperative management of special populations: obesity. Surg Clin North Am 85:1283-1289. doi:10.1016/j.suc.2005.09.002 (p xii)

9. Bhandari S, Agrawal P, Singh A. Body Mass Index and Its Role in Total Laparoscopic Hysterectomy. Int Sch Res Notices. 2014;2014: 787604. Published 2014 Oct 28. doi:10.1155/2014/ 787604.

10. EltabbakhGH,PiverMS,HemplingRE,RecioFO.Laparoscopic surgery in obese women. ObstetGynecol 1999; 94(5 Pt 1):704-8.

11. Pasic R, Levine RL, Wolf WM, Jr. Laparoscopy in morbidly obese patients. J Am Assoc GynecolLaparosc 1999; 6(3):307-12.

12. Saito A, Hirata T, Koga K, Takamura M, Fukuda S, Neriishi K, et al. Preoperative assessment of factors associated with difficulty in performing total laparoscopic hysterectomy. J ObstetGynaecol Res 2017;43:320-9.

13. Guraslan H, Senturk MB, Dogan K, Guraslan B, Babaoglu B, Yasar L. Total laparoscopic hysterectomy in obese and morbidly obese women. GynecolObstet Invest. 2015;79(3):184-8. doi: 10.1159/ 000367658. Epub 2015 Feb 4. PMID: 25660528.

14. Bardens D, Solomayer E, Baum S, Radosa J, Gräber S, Rody A, JuhaszBöss I.The impact of the body mass index (BMI)on laparoscopic hysterectomy for benign disease.Arch Gynecol Obstet. 2014 Apr;289(4):803-7. doi: 10.1007/s00404-013-3050-2. Epub 2013 Oct 11.

15. Bogani G, Cromi A, Serati M, Di Naro E, Casarin J, Pinelli C, Uccella S, Leone Roberti Maggiore U, Marconi N, Ghezzi F. Laparoscopic and vaginal approaches to hysterectomy in the obese. Eur J Obstet GynecolReprod Biol. 2015 Jun;189:85-90. doi: 10.1016/j.ejogrb. 2015.02.035. Epub 2015 Apr 10. PMID: 25898369.

16. Blikkendaal MD, Schepers EM, van Zwet EW, Twijnstra AR, Jansen FW. Hysterectomy in very obese and morbidly obese patients: a systematic review with cumulative analysis of comparative studies. Arch Gynecol Obstet. 2015 Oct;292(4):723-38. doi: 10.1007/ s00404-015-3680-7. Epub 2015 Mar 13. PMID: 25773357; PMCID: PMC4560773.

17. Chopin N, Malaret JM, Lafay-Pillet MC, Fotso A, Foulot H, Chapron C. Total laparoscopic hysterectomy for benign uterine pathologies: obesity does not increase the risk of complications. Hum Reprod. 2009 Dec;24(12):3057-62. doi: 10.1093/humrep/dep348. Epub 2009 Oct 3. 